\title{
O domínio patrimônio cultural na formação do
}

bibliotecário: interseções e possibilidades de abordagem no Currículo do Curso de Biblioteconomia da Universidade Federal do Maranhão

The cultural heritage domain in the formation of the librarian: intersections and possibilities of approach in the curriculum of the Librarianship course of the Federal University of Maranhão

El dominio del patrimonio cultural en la formación de la biblioteca: intersecciones y posibilidades de enfoque en el Currículo del Curso de Biblioteconomía de la Universidad Federal de Maranhão

\author{
Maurício José Morais COSTA ${ }^{1}$ \\ Valdirene Pereira da CONCEIÇÃO ${ }^{2}$ \\ Donny Wallesson dos SANTOS 3 \\ Kláutenys Dellene Guedes CUTRIM ${ }^{4}$
}

\section{Correspondência}

Autor para correspondência: Maurício José Moraes Costa.

Endereço completo. Endereço: Avenida Gapara, 4 A, Estrada do Gapara,

CEP: 65083-430

E-mail: mauriciojosemorais@gmail.com

ORCID- https://orcid.org/0000-0002-0759-

$\underline{9285}$

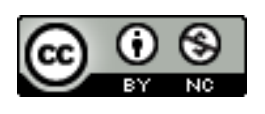

Submetido em: 01/12/2019

Aceito em: 02/01/2020

Publicado em: 22/05/2020

\footnotetext{
${ }^{1}$ Mestre em Cultura e Sociedade pela Universidade Federal do Maranhão (PGCULT-UFMA) e Professor do Centro Universitário Unidade de Ensino Superior Dom Bosco (UNDB).

${ }^{2}$ Doutora em Linguística e Língua Portuguesa pela Universidade Estadual Paulista "Júlio de Mesquita Filho" (UNESP) e Professora Associada do Departamento de BiblioteconomiaUFMA.

${ }^{3}$ Doutorando no Programa de Pós-Graduação em Políticas Públicas e Mestre em Cultura e Sociedade pela Universidade Federal do Maranhão (UFMA).

${ }^{4}$ Doutora em Linguística e Língua Portuguesa pela Universidade Estadual Paulista "Júlio de Mesquita Filho" (UNESP) e professora do Departamento de Turismo e Hotelaria e do Programa de Pós-Graduação em Cultura e Sociedade (PGCULT/UFMA).
} 


\section{RESUMO}

Inserção dos estudos em patrimônio cultural na formação do bibliotecário. Trata-se de uma pesquisa bibliográfica e documental, de natureza exploratória com fins analíticos e descritivos, acerca do currículo do Curso de Biblioteconomia da Universidade Federal do Maranhão com objetivo de analisar as possibilidades de interseção e abordagem do patrimônio cultural na formação de seus bibliotecários. Discute os conceitos de patrimônio cultural em autores como Cutrim (2011), Choay (2001), Castro (2008), além de um recorte histórico da evolução curricular da Biblioteconomia por meio de Pinto (2015), Castro (2000), Fonseca (1979) e Almeida e Baptista (2013), dentre outros autores. Detém-se na análise do currículo da Biblioteconomia em vigor na UFMA para fins de identificação de disciplinas, núcleo e eixos que possam se relacionar com o tema do patrimônio cultural. Resulta na constatação da ausência de disciplinas que tratem especificamente do tema, porém detecta possibilidades transversais de inserção dos conteúdos referentes ao patrimônio cultural nos eixos estruturantes da matriz curricular do curso analisado. Ressalta ainda a necessidade de outros estudos que investiguem as interseções entre o patrimônio cultural e formação do bibliotecário, haja vista ele fazer parte do escopo da sua prática, promovendo a democratização da informação referente aos bens culturais, materiais e imateriais, e seus desdobramentos.

Palavras-chave: Análise de Currículo na Biblioteconomia. Curso de Biblioteconomia da UFMA. Patrimônio Cultural na Biblioteconomia. Patrimônio Cultural e Formação do Bibliotecário.

\section{ABSTRACT}

Analysis of the possibilities of intersection of studies in cultural heritage in the formation of the librarian. This is a bibliographic and documentary research, of an exploratory nature with analytical and descriptive purposes, about the curriculum of the Bibliotheconomia course of the Universidade Federal do Maranhão with the objective of analyzing the possibilities of intersection and Cultural heritage approach in the formation of its librarians. It discusses the concepts of cultural heritage in authors such as Cutrim (2011), Choay (2001), Castro (2008), in addition to a historical excerpt from the curricular evolution of Bibliotheconomia through Pinto (2015), Castro (2000), Fonseca (1979) and Almeida and Baptista (2013), Among other authors. It is held in the analysis of the curriculum of Bibliotheconomia in force in the UFMA for purposes of identification of disciplines, nucleus and axes that can relate to the theme of cultural heritage. It results in the observation of the absence of disciplines that deal specifically with the theme, but detects transversal possibilities of inserting the contents referring to cultural heritage in the structuring axes of the curriculum matrix of the analyzed course. It also emphasizes the need for other studies that investigate the intersections between the cultural heritage and the formation of the librarian, given 
that it is part of the scope of its practice, promoting the democratization of information concerning cultural goods, Materials and immaterial, and their developments.

Keywords: Cultural Heritage and Training of the Librarian. Cultural Heritage in Librarianship. Curriculum Analysis in Librarianship. UFMA Librarianship Course.

\section{RESUMEN}

Inserción de estudios sobre patrimonio cultural en la formación de bibliotecarios. Esta es una investigación bibliográfica y documental, de naturaleza exploratoria con fines analíticos y descriptivos, sobre el plan de estudios del Curso de Biblioteconomía de la Universidad Federal de Maranhão para analizar las posibilidades de intersección y enfoque del patrimonio cultural en la formación de sus bibliotecarios. Discute los conceptos del patrimonio cultural en autores como Cutrim (2011), Choay (2001), Castro (2008), además de un resumen histórico de la evolución curricular de la biblioteconomía a través de Pinto (2015), Castro (2000), Fonseca (1979) y Almeida y Baptista (2013), entre otros autores. Analiza el plan de estudios de Bibliotecología vigente en la UFMA con el fin de identificar disciplinas, núcleos y ejes que puedan relacionarse con el tema del patrimonio cultural. Resulta en la verificación de la ausencia de disciplinas que aborden específicamente el tema, pero detecta posibilidades transversales de inserción de los contenidos referentes al patrimonio cultural en los ejes estructurantes de la matriz curricular del curso analizado. También destaca la necesidad de otros estudios que investiguen las intersecciones entre el patrimonio cultural y la formación de bibliotecarios, dado que es parte del alcance de su práctica, promoviendo la democratización de la información sobre bienes culturales, materiales e inmateriales, y sus consecuencias.

Palabras clave: Análisis curricular en biblioteconomía. Curso de Biblioteconomía UFMA. Patrimonio Cultural en Biblioteconomía. Patrimonio cultural y formación de bibliotecarios.

\section{INTRODUÇÃO}

A sociedade passou por grandes transformações nos últimos anos, implicando em mudanças econômicas, políticas, sociais e informacionais. O acelerado desenvolvimento das tecnologias, faz com que o principal insumo de trabalho do bibliotecário - a informação - tornando sua produção e disseminação em diferentes canais comunicacionais. Sendo a 
informação e as tecnologias a base da economia, se explicitam novos documentos, por sua vez apresentam distintas manifestações, expressões, materializações e imaterializações.

Nesse sentido, tem-se informações que necessitam de tratamento, visando atender de forma significativa as necessidades de informação da sociedade brasileira, na perspectiva de assegurar a igualdade e a efetivação da cidadania nos mais diferentes lócus brasileiros. Cada região do Brasil é composta por elementos que os distinguem, saberes e fazeres que constituem sua memória, sua identidade, ou seja, seu patrimônio. Esses documentos (independente de sua forma) deve ser compreensível, acessível e apropriado pelos seus detentores de direito.

A formação do bibliotecário maranhense deve prepará-lo para a complexidade cultural do Estado, tendo em vista seu papel e sua responsabilidade, que extrapola a mera gestão de unidades de informação, colocando-o como mediador, educador e difusor da cultura local. Nessa assertiva, emerge-se a seguinte problemática: Quais as possibilidades de interseções e de abordagem do patrimônio cultural na formação do bibliotecário no currículo do Curso de Biblioteconomia da Universidade Federal do Maranhão?

Por tanto, o presente estudo tem por objetivo geral analisar as possibilidades de interseção e abordagem do patrimônio cultural na formação do bibliotecário no Curso de Biblioteconomia da Universidade Federal do Maranhão. Além disso, pretende-se refletir acerca da necessidade de o 
patrimônio cultural estar presente nas práticas biblioteconômicas, visto se tratar de um importante objeto de trabalho do bibliotecário maranhense. Trata-se de um estudo exploratório, com fins analíticos e descritivos, que fez uso da pesquisa bibliográfica e documental como instrumentos de fundamentação teórica. Para tanto valeu-se de autores como Castro (2000), Pinto (2015), Mueller (1985), Almeida e Batista (2013), Conceição, Vetter e Costa (2013), dentre outros.

\section{DOMÍNIO PATRIMÔNIO CULTURAL}

A concepção de patrimônio apresenta-se como importante fator na construção da identidade dos sujeitos, de um território ou de uma nação, pois permite a demarcação de narrativas, signos e símbolos que representam a sua história, compreendendo o presente pela preservação do passado e, assim, colocando o futuro em perspectiva. Para Cutrim (2011), visto como signo ideológico, o patrimônio se modifica ao longo da história, ao passo que se reconfigura a partir de novas definições do que pode ser considerado patrimônio.

Derivada do latim, patrimonium, significava na Roma Antiga tudo aquilo que pertencia ao pai de família, desde os bens materiais à esposa, filhos e escravos. Já na Idade Média, relaciona-se principalmente com a preservação histórica de grandes monumentos, pela prerrogativa do seu valor artístico e cognitivo para a memória, que se institucionaliza séculos depois, no Iluminismo, mediante a criação dos primeiros museus, com o intuito de conservar a memória de maneira 
sistemática e democratizar o acesso da população a ela. Porém, é na Revolução Francesa que essa lógica se fortalece em virtude da construção de uma identidade nacional, advinda da ameaça concreta de perda dos monumentos históricos em virtude das guerras (CASTRO, 2008; CHOAY, 2001; FONSECA, 2005).

A percepção de patrimônio inicialmente tida como propriedade privada dá lugar ao interesse cultural coletivo, cunhando a noção de patrimônio cultural na Constituição de 1988 que contempla não somente o valor histórico e artístico, mas amplia para o campo da ciência e tecnologia, manifestações artísticas populares, paisagens, conjuntos urbanos, sítios históricos e arqueológicos, dentre outros (BRASIL, 1988).

Martins (2009, p. 305) advoga pela diversificação de fontes para o estudo e compreensão do patrimônio cultural, haja vista que este se renova a partir de cada temática ou cada objeto de análise. Em outras palavras, compreendê-lo é "[...] um exercício constante de descoberta das representações dinâmicas da história [...]". logo, é salutar analisar o patrimônio cultural por óticas que superam as noções de preservação tradicionais, compreendendo o patrimônio como matéria viva que se renova pela ação dos agentes em seu contexto e se relaciona com outras esferas da vida humana.

Camargo (2006) coloca que as diretrizes das políticas públicas de proteção ao patrimônio cultural obtiveram um grande avanço ao reconhecer a pluralidade cultural do país, a 
fim de atingir as microrregiões e iniciar um processo de descentralização dos bens simbólicos da nação, no sentido de que o Brasil com sua diversidade cultural constrói narrativas de patrimônio cultural diferenciadas para cada região, de acordo com a memória e a identidade construídas historicamente em cada território. Consoante, busca-se compreender as possibilidades da interlocução dos conceitos sobre o tema para a atuação do bibliotecário, partindo da assertiva evolução histórica de suas atribuições que abarcam o escopo do patrimônio cultural, em especial suas implicações no currículo do curso de Biblioteconomia da UFMA, as ressignificações ao longo da história, bem como as múltiplas abordagens possíveis dentro do campo, abordadas nas seções seguintes.

\section{A FORMAÇÃO DO BIBLIOTECÁRIO NO MARANHÃO}

O ensino de Biblioteconomia no Brasil teve sua trajetória iniciada na Biblioteca Nacional (BN), no Rio de Janeiro, por volta de 1911. A BN passou a oferecer um curso específico para formar bibliotecários, por sua vez, fortemente influenciado pela escola francesa École de Nationale des Chartes. A formação era destinada aos profissionais da própria instituição, que necessitavam de qualificação específica (PINTO, 2015; CASTRO, 2000). Destaca-se que o curso de Biblioteconomia ofertado pela BN, era de cunho humanístico, e tinha como principal pré-requisito "possuir cultura geral" (ALMEIDA; BAPTISTA, 2013, p. 2). O segundo curso de Biblioteconomia aberto no Brasil foi aberto em 1929, no Mackenzie College, por 
sua vez influenciado pela escola americana tecnicista Columbia University, sob os auspícios da bibliotecária Dorothy Muriel (PINTO, 2015; MUELLER, 1985). Conforme explica Castro (2000), o curso estava voltado para os funcionários da biblioteca, bem como professores e bibliotecários de outras instituições.

A partir disso, outras instituições se preocuparam em organizar cursos destinados à formação de bibliotecários (RUSSO, 1966). Castro (2000) complementa acentuando que a década de 1940 foi decisiva para a ampliação do objeto de trabalho do bibliotecário, pois novas metodologias de gestão e organização de bibliotecas entravam em evidência, em especial os sistemas de classificação e catalogação. Mediante a instauração de um novo currículo, tornou-se obrigatória a necessidade de registro dos diplomas no Ministério da Educação, elevando os cursos de Biblioteconomia para nível superior. Finda que em 1962 os cursos de graduação na área foram implementados nas universidades brasileiras, a partir de um currículo mínimo, composto por 10 (dez) matérias, divididas em técnicas e culturais/humanísticas (PINTO, 2015).

Todavia, a estrutura curricular passou novamente por modificações, a partir da necessidade de atualização em 1982, resultando no Segundo Currículo Mínimo de Biblioteconomia, cujas disciplinas dividiam-se em três eixos: a) fundamentação geral; b) instrumentais e; c) formação profissional (ALMEIDA; BAPTISTA, 2013). Destaca-se que o currículo de 1982 era praticamente igual ao de 1962, embora a intenção fosse 
abandonar o tecnicismo, em prol de um entendimento mais consubstanciado das implicações dos conhecimentos envolvidos na formação do bibliotecário.

Diante do descontentamento da classe e de acadêmicos do campo da Biblioteconomia, o currículo viria a passar por novas alterações. Sob influência da Lei 9.394, de 20 de dezembro de 1996 (Lei de Diretrizes e Bases da Educação Nacional), que conferiu autonomia para as Universidades criarem, organizarem e extinguirem cursos e programas de educação superior (ALMEIDA; BATISTA, 2013). Com isso, em 2001 foram apresentadas as Diretrizes Curriculares Nacionais para o ensino de Biblioteconomia, reforçando as competências, habilidades, bem como a importância dos estágios, atividades curriculares complementares, avaliação institucional e estrutural dos cursos.

Com a expansão da demanda por bibliotecários, o ensino necessitou de novas adequações, culminando nas Diretrizes Curriculares Nacionais para a formação de bibliotecários, fato que foi decisivo para que as universidades pudessem direcionar melhor seus currículos. Nesse interim, destaca-se o Curso de Biblioteconomia da Universidade Federal do Maranhão (UFMA), a ser abordado na seção seguinte.

\subsection{Curso de Biblioteconomia da UFMA}

O Curso de Biblioteconomia da UFMA foi criado há mais de cinquenta anos, e ao longo de sua trajetória, tem formado os bibliotecários no Estado do Maranhão. Instituído pela Resolução No 84, de 10 de março de 1969, a partir da necessidade de 
qualificarem-se profissionais para atuarem nas diferentes bibliotecas em São Luís e nas demais cidades do Estado (PROJETO..., 2006; CONCEIÇÃO; VETTER; COSTA, 2013).

Reconhecido e iniciado na então Fundação Universidade do Maranhão (FUM), o Curso de Biblioteconomia adotou, inicialmente, a estrutura curricular nacional. Todavia, o processo de reavaliação do currículo do curso em nível nacional, também se estendeu ao cenário local, culminando na reestruturação curricular, visto às demandas e transformações sociais da época (CONCEIÇÃO; VETTER; COSTA, 2013). Na perspectiva de atender aos interesses e necessidades da sociedade, o Curso de Biblioteconomia da UFMA passou por quatro reformas curriculares desde sua criação em 1969, cuja evolução pode ser observada no Quadro 1 (PROJETO..., 2006).

Quadro 1 - Currículos de Biblioteconomia da UFMA

\begin{tabular}{|c|c|c|c|c|}
\hline & $\begin{array}{c}\text { CURRÍCULO } \\
\text { "0" }\end{array}$ & $\begin{array}{c}\text { CURRÍCULO } \\
\text { "10" }\end{array}$ & $\begin{array}{c}\text { CURRÍCULO } \\
\text { "20" }\end{array}$ & $\begin{array}{c}\text { CURRÍCULO } \\
\text { "30" }\end{array}$ \\
\hline VIGÊNCIA & $1969-1983$ & $1983-1997$ & $1997-2006$ & $\begin{array}{c}2007 \text { até } \\
\text { hoje }\end{array}$ \\
\hline CARGA \\
HORÁRIA
\end{tabular}

Como pode ser observado no Quadro 1, o Curso adotou quatro currículos, sendo que o Currículo "30" encontra-se em vigor, cuja carga horária reúne disciplinas concentradas no gerenciamento da informação, logo propõe-se a formar profissionais para atuarem em diferentes bibliotecas (PROJETO..., 2006). Destaca-se que o Curso de Biblioteconomia 
por meio de seu Núcleo Docente Estruturante (NDE) vêm se dedicando à revisão e reestruturação de um novo currículo, que contemplará os aspectos postos aos bibliotecários nos últimos anos.

Diante disso, ressalta-se que o Estado do Maranhão apresenta não apenas um cenário complexo e diversificado em termos de unidades de informação, mas, sobretudo diferentes expressões e manifestações informacionais. Notadamente, sendo o patrimônio cultural objeto de trabalho do bibliotecário maranhense, emerge-se a necessidade de o currículo de Biblioteconomia da UFMA levar em consideração tal fato, para tanto, na próxima seção explicitam-se as possibilidades de implementação e abordagem do domínio patrimônio cultural na formação de tal profissional.

\section{O PATRIMÔNIO CULTURAL NA FORMAÇÃO DO BIBLIOTECÁRIO: implicações no currículo de Biblioteconomia da UFMA}

Diante da ampliação das demandas e exigências postas ao bibliotecário, impulsionadas pelas transformações sociais, tanto os locais, quanto as formas de atuação desse profissional foram ressignificadas. Fato é que a matéria-prima de trabalho - a informação - modificou-se, apresentando novas frentes de tratamento, organização e disseminação da informação, bem como variados ambientes e suportes informacionais.

Nesse sentido, Mata e Casarin (2010) explicam que as mudanças no objeto de trabalho, revelam a necessidade de revisão e rediscussão dos conteúdos e planos por parte das 
escolas de Biblioteconomia. Silveira (2007) afirma que o sistema de ensino estabelecido no Brasil, mesmo passando por reformulações, ainda privilegia as atividades técnicas de gestão de acervos. Deixa-se de lado a participação social do bibliotecário, bem como a preservação dos elementos culturais, dos símbolos e lugares de memória. Partindo disso, destaca-se o currículo "30", em vigor no Curso de Biblioteconomia da UFMA, divide suas disciplinas em três eixos, por suas vezes compostos por núcleos, com suas respectivas cargas horárias, distribuição pode ser vista no Quadro 2:

Quadro 2 - Currículos de Biblioteconomia da UFMA

\begin{tabular}{|c|c|c|c|}
\hline & $\begin{array}{c}\text { EIXO I - } \\
\text { Biblioteconomia e } \\
\text { Ciências } \\
\text { Interdisciplinares }\end{array}$ & $\begin{array}{c}\text { EIXO II - } \\
\text { Construção das } \\
\text { práticas } \\
\text { profissionais }\end{array}$ & $\begin{array}{c}\text { EIXO III - } \\
\text { Construção da } \\
\text { prática de } \\
\text { pesquisa e } \\
\text { atividades } \\
\text { profissionais }\end{array}$ \\
\hline \multirow{2}{*}{\begin{tabular}{l}
$n$ \\
0 \\
$u$ \\
$u$ \\
\hdashline \\
$z$
\end{tabular}} & $\begin{array}{c}\text { Núcleo } 1 \text { : Estudos } \\
\text { sobre o pensamento } \\
\text { científico e as relações } \\
\text { sóciohistóricas. }\end{array}$ & $\begin{array}{c}\text { Núcleo 1: Estudos } \\
\text { sobre Processamento } \\
\text { e Tecnologia da } \\
\text { Informação }\end{array}$ & $\begin{array}{c}\text { Núcleo 1: } \\
\text { Investigação e } \\
\text { práticas } \\
\text { profissionais em } \\
\text { Biblioteconomia. }\end{array}$ \\
\hline & $\begin{array}{l}\text { Núcleo 2: Estudos } \\
\text { sobre a relação } \\
\text { Informação e } \\
\text { Sociedade }\end{array}$ & \begin{tabular}{l} 
Núcleo 2: Estudos \\
sobre Gestão e \\
Organização dos \\
Produtos e Serviços \\
\multicolumn{2}{c}{ Informacionais } \\
\end{tabular} & $\begin{array}{l}\text { Núcleo 2: Estudos } \\
\text { complementares e } \\
\text { de formação } \\
\text { continuada }\end{array}$ \\
\hline
\end{tabular}

Fonte: Projeto Político Pedagógico de Biblioteconomia (2006)

O Eixo I promove o diálogo da Biblioteconomia com diferentes áreas do conhecimento, tais como Antropologia, Sociologia, Linguística, Comunicação, Filosofia, dentre outras (PROJETO..., 2006). Nesse eixo, se pode identificar campos transversais e que podem ser oportunidades de abordagem do patrimônio cultural, visto se tratar de um domínio que perpassa 
questões sociais, antropológicas e epistemológicas. Sendo o patrimônio uma construção discursiva, que não apenas demarca os aspectos simbólicos e culturais, também encontra terreno na Linguística e na Comunicação (CHOAY, 2001).

Destaca-se que a construção curricular de um curso de graduação deve levar em consideração o contexto sóciohistórico no qual a universidade está inserida, não devendo se restringir às questões técnicas e metodológicas (CONCEIÇÃO; VETTER; COSTA, 2013). Assim sendo, é necessário que as questões relacionadas à cultura local, bem como os patrimônios material e imaterial sejam contempladas no currículo de Biblioteconomia no Maranhão, pois as práticas bibliotecárias no Estado devem pautar-se nas necessidades específicas dos usuários locais.

Os aspectos específicos da construção das práticas profissionais do bibliotecário estão concentrados nos Eixos II e III. Neles estão disciplinas técnicas que capacitam o profissional para o processamento de documentos, organização de acervos, produtos e serviços de unidades de informação, além de trabalhar as competências de pesquisa do bibliotecário. Os objetos, os artefatos e documentos alvo da prática bibliotecária, contempla diferentes conhecimentos registrados nos mais distintos suportes, dados, informações, ou seja, toda e qualquer evidência que possa servir de fonte para as pessoas.

Partindo da diversidade documental que permeia as bibliotecas, evidencia-se o patrimônio cultural, que por sua vez se expressa materialmente (livros, manuscritos, artefatos 
raros, monumentos, entre outros) e imaterialmente (saberes populares, simbolismos, danças, rituais tradicionais, modo de fazer etc.). O patrimônio, enquanto domínio transversal pode ter múltiplas abordagens no Curso de Biblioteconomia, conforme pode ser analisado no Quadro 3, as relações estabelecidas com as disciplinas.

Quadro 3 - Possibilidades de abordagens do domínio patrimônio cultural no curso de BI

\begin{tabular}{|c|c|c|c|c|}
\hline & & OBJETIVO & DISCIPLINAS & $\begin{array}{l}\text { ABORDAGENS } \\
\text { TRANSVERSAIS }\end{array}$ \\
\hline 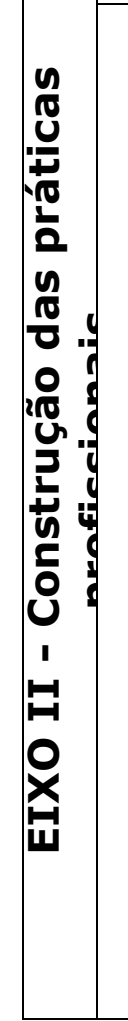 & 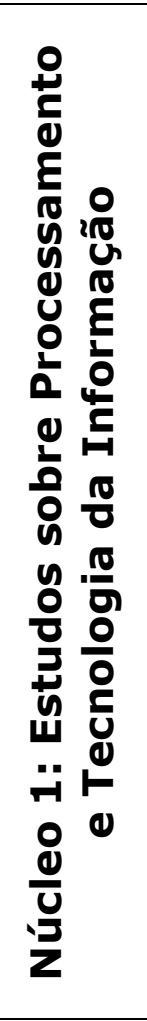 & $\begin{array}{l}\text { Agregar } \\
\text { saberes e } \\
\text { práticas em } \\
\text { torno do } \\
\text { processam } \\
\text { ento da } \\
\text { informação } \\
\text { registrada } \\
\text { em meios } \\
\text { tradicionais } \\
\text { e } \\
\text { eletrônicos }\end{array}$ & $\begin{array}{c}\text { Representação } \\
\text { Descritiva I e II } \\
\text { Linguagem } \\
\text { Documentária } \\
\text { I, II e III } \\
\text { Controle dos } \\
\text { Registros do } \\
\text { Conhecimento }\end{array}$ & $\begin{array}{l}\text { Descrição de obras, artefatos } \\
\text { e peças locais; } \\
\text { Apresentar aos alunos } \\
\text { objetos que irão encontrar } \\
\text { nas diferentes bibliotecas } \\
\text { (mapas, músicas } \\
\text { maranhenses, monumentos, } \\
\text { obras de arte, dentre outros } \\
\text { itens documentais); } \\
\text { Classificação de conteúdos } \\
\text { específicos (identificação de } \\
\text { assuntos locais, classificações } \\
\text { mais próximas possíveis); } \\
\text { Constituição de vocabulários } \\
\text { controlados com expressões, } \\
\text { termos, terminologias, } \\
\text { domínio tipicamente } \\
\text { maranhenses; } \\
\text { Privilegiar obras locais nas } \\
\text { exemplificações. }\end{array}$ \\
\hline
\end{tabular}




\begin{tabular}{|c|c|c|c|}
\hline 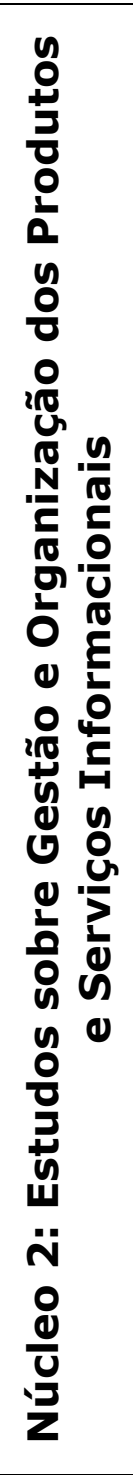 & $\begin{array}{c}\text { Reunir } \\
\text { conteúdos } \\
\text { que tratem } \\
\text { do } \\
\text { gerenciame } \\
\text { nto, } \\
\text { organizaçã } \\
\text { o de } \\
\text { produtos e } \\
\text { serviços } \\
\text { informacio } \\
\text { nais em } \\
\text { diferentes } \\
\text { sistemas } \\
\text { de } \\
\text { informação } \\
\text {. }\end{array}$ & $\begin{array}{c}\text { Referência } \\
\text { Formação e } \\
\text { Desenvolvimen } \\
\text { to de Coleções } \\
\text { Marketing em } \\
\text { Unidades de } \\
\text { Informação } \\
\text { Fontes de } \\
\text { Informação } \\
\text { Arquivística } \\
\text { Gestão de } \\
\text { Bibliotecas } \\
\text { Especializadas } \\
\text { e Universitárias } \\
\text { Gestão de } \\
\text { Bibliotecas } \\
\text { Públicas e } \\
\text { Escolares }\end{array}$ & $\begin{array}{l}\text { Relacionar os aspectos } \\
\text { colocais ao Serviço de } \\
\text { Referência e Informação } \\
\text { (SRI); } \\
\text { Discutir a elaboração de } \\
\text { políticas de formação e } \\
\text { desenvolvimento de coleções } \\
\text { a necessidade de se } \\
\text { considerar a cultura e os } \\
\text { saberes locais, cujos acervos } \\
\text { devem contemplar obras que } \\
\text { venham sanar as } \\
\text { necessidades informacionais } \\
\text { dos cidadãos maranhenses; } \\
\text { O patrimônio material e } \\
\text { imaterial é uma importante } \\
\text { fonte de informação, logo sua } \\
\text { abordagem na disciplina de } \\
\text { Fontes de Informação é } \\
\text { essencial; } \\
\text { As bibliotecas (públicas, } \\
\text { privadas, especializadas, } \\
\text { universitárias, escolares, } \\
\text { etc.) contém em seu acervo } \\
\text { obras maranhenses, tão logo } \\
\text { a articulação do patrimônio } \\
\text { nesses espaços de interação } \\
\text { e intersubjetividades é } \\
\text { basilar. }\end{array}$ \\
\hline
\end{tabular}

Fonte: adaptado do Projeto Político Pedagógico de Biblioteconomia (2006)

Como pôde ser observado no Quadro 3, as disciplinas apresentam transversalidade ao domínio do patrimônio cultural, sendo possível a articulação das abordagens com a referida temática. Figueiredo (2018) em seu estudo reforçou a necessidade de a estrutura curricular adotar em sua dinâmica elementos da cultura local, ou seja, registros produzidos no Maranhão. Desse modo, afirma-se que "[...] o currículo deve contemplar não só a dimensão educacional, mas também política, social e cultural." (FIGUEIREDO, 2018, p. 45), visto se 
tratar de elementos que estão presentes nas bibliotecas maranhenses, sendo assim, um conhecimento necessário para os bibliotecários que atuarão nestas.

Embora o currículo "30" apresente em seu objetivo geral o intuito em graduar bibliotecários capazes de transformar a realidade histórico-cultural, bem como atender às necessidades informacionais, a partir dos múltiplos suportes no contexto social em vigência, não é possível identificar em sua estrutura curricular disciplinas específicas (ou optativas) que versem sobre a cultura local, ou que pontuem a abordagem do patrimônio cultural. Destaca-se que outras escolas de Biblioteconomia contam com disciplinas voltadas para o patrimônio, memória e cultura local, como pode ser visto no Quadro 4:

Quadro 4 - Escolas de BI com disciplinas voltadas ao patrimônio, memória e cultura

\section{DISCIPLINAS E ESCOLAS}

Informação, Memória e Sociedade (UFPB) / História e Cultura de Alagoas (UFAL) / Tópicos Especiais em Ciência da Informação 2 (Memória, Espaços memoriais, Patrimônio material e imaterial) e Ações, Instituições e Bens Culturais (UFPE) / Memória e Patrimônio Cultural (UFMG) / História do Rio Grande do Sul aplicada à Ciência da Informação; Informação e Memória Social; e Produção e Gestão Cultural (UFRGS) / Cordel, Informação e Memória e Fotografia e Memória (UFCA) Informação, Memória e Documento (UNIRIO) / História da Cultura e Cultura Brasileira (UFRN) / Cultura e informação (UFMG) / História do Brasil contemporâneo e Sociologia e Cultura (UFSC).

Fonte: Dados da pesquisa (2019)

O Quadro 4 lista algumas escolas de Biblioteconomia que trazem em sua estrutura curricular disciplinas voltadas para a cultura, mais precisamente à aspectos locais e ao patrimônio 
cultural, como por exemplo a UFCA, UFMG e UFRGS. Pontua-se que a UFMA estando situada em uma cidade Patrimônio Mundial, próxima ao Centro Histórico de São Luís tombado pela UNESCO, e que por sua vez conta com um número significativo de bibliotecas, ainda não dispõe de uma disciplina específica para tal diversidade documental. Sant'Anna (2017, p. 92) afirma que "[...] o espaço da biblioteca passa a ser um local de geração, de transmissão e de redefinição da cultura [...]", portanto, não deve haver a distância do currículo do curso com os espaços de trabalho do bibliotecário no Maranhão, uma vez que a sociedade demanda por um profissional que seja também um mediador cultural.

Figueiredo (2018), Conceição, Vetter e Costa (2013) já reforçavam em seus estudos a necessidade de revisão curricular, na perspectiva de incluírem-se conteúdos alinhados à realidade informacional local, que privilegie os saberes e os registros peculiares do Estado do Maranhão, tendo em vista que o bibliotecário tem assumido o papel de "[...] mediador cultural que, precisar ter domínio dos saberes e dinâmica para atender as diferentes demandas." (FIGUEIREDO, 2018, p. 46).

As bibliotecas do Estado do Maranhão, notadamente aquelas instaladas nos centros culturais, a biblioteca Roldão Lima (especializada em Cultura Popular Maranhense e está vinculada ao Centro de Cultura Popular Domingos Vieira Filho), a Biblioteca Pública Benedito Leite (BPBL), dentre outras, são aparelhos culturais cujos acervos são compostos por patrimônios materiais e imateriais, cabendo aos bibliotecários 
inseridos nelas tratarem, organizarem, disseminarem e mediarem tais informações, que demanda formação específica.

\section{CONSIDERAÇÕES FINAIS}

Nota-se que a evolução histórica do conceito de patrimônio cultural permitiu ampliar o universo identitário do Brasil, mediante o reconhecimento da pluralidade de bens culturais e simbólicos, buscando compreender os impactos deste não somente em nível macrorregional, mas sim nas singularidades partilhadas por cada território, que geram demandas específicas de políticas públicas.

É nesse pensamento que a formação do bibliotecário evolui historicamente, saindo das primeiras organizações curriculares tecnicistas e passa a contemplar outras habilidades e competências que correspondam às necessidades de expansão dos conteúdos que agreguem a dimensão humana e cultural da Biblioteconomia. Em recorte, o Curso de Biblioteconomia da UFMA segue o padrão e passa por quatro reformas curriculares a fim de corresponder as demandas sociais e à velocidade de produção e difusão da informação do novo século.

No currículo em vigor na UFMA, embora não existam disciplinas específicas na Biblioteconomia, encontram-se brechas em seus eixos estruturantes que possibilitam a inserção do tema do patrimônio cultural, em virtude da extensa relação transversal com outras áreas do saber e da necessária correlação da produção universitária com seu entorno e seu 
contexto social, contemplando aspectos da cultura local, da memória da comunidade e dos espaços históricos que a compõem, sinalizando a necessidade de outros estudos que abarquem tais aspectos detidamente.

Assim, a evolução do conceito de patrimônio cultural impacta diretamente as políticas públicas e seus equipamentos, sejam elas de preservação, culturais ou educacionais. Não obstante, faz-se necessário aplicar essa percepção holística para compreender o funcionamento dos contextos sociais. Estudar o patrimônio não é mais olhar somente para o passado, mas sim evidenciar as relações presentes com a memória cultural, seus bens simbólicos e os agentes sociais inseridos em seu contexto, gerindo os conflitos e interesses das instâncias da sociedade que contemplem as demandas da população, garantindo direitos e efetivando a democratização cultural.

\section{REFERÊNCIAS}

ALMEIDA, N. B. F.; BAPTISTA, S. G. Breve histórico da Biblioteconomia brasileira: formação do profissional. In: CONGRESSO BRASILEIRO DE BIBLIOTECONOMIA, DOCUMENTAÇÃO E CIÊNCIA DA INFORMAÇÃO, 25., 2013.

Anais[...] Florianópolis: FEBAB, 2013.

\section{BRASIL. Constituição da República Federativa do Brasil de} 1988. Brasília, DF: Diário Oficial da União, 1988.

CAMARGO, C. R. A construção da memória na sociedade global. Identidades sociais: local x global. Patrimônio e Memória, São Paulo, v. 2, p. 45-53, 2006.

CASTRO, C. A. História da Biblioteconomia Brasileira: perspectiva histórica. Brasília, DF: Thesaurus, 2000. 287p. 
CASTRO, C. História, cultura e patrimônio documental. In:

CASTRO, C. Pesquisando em arquivos. Rio de Janeiro: Ed. Jorge Zahar, 2008.

CHOAY, F. A alegoria do patrimônio. São Paulo: Editora UNESP, 2001.

CONCEIÇÃO, V. P.; VETTER, S. M. J.; COSTA, M. J. M. A catalogação nos currículos do Curso de Biblioteconomia do Maranhão. In: ENCONTRO INTERNACIONAL DE CATALOGAÇÃO, 9., 2013. Anais[...] Rio de Janeiro: BN, 2013.

CUTRIM, K. D. G. Patrimônio da humanidade: a edificação discursiva da cidade de São Luis nas políticas de preservação do Estado. 2011. 187f. Tese (Doutorado) - Universidade Estadual Paulista, Araraquara, 2011.

FIGUEIREDO, F. B. Elementos da cultura popular maranhense na formação do bibliotecário: o simbolismo do bumba meu boi. 2018. 67f. Monografia (Bacharelado em Biblioteconomia) - Universidade Federal do Maranhão, São Luís, 2018.

FONSECA, M. C. L. O patrimônio em processo: trajetória da política federal da preservação no Brasil. 2. ed. Rio de Janeiro: Editora UFRJ. IPHAN, 2005.

MARTINS, A. L. Fontes para o patrimônio cultural. Uma construção permanente. In: LUCA, T. R.; PINSKY, C. B. (Org.). O historiador e suas fontes. São Paulo: Contexto, 2009. p. 281-305.

MATA, M. L. ; CASARIN, H. C. S. A formação do bibliotecário e a competência informacional: um olhar através das competências. In: VALENTIM, M. (Org.). Gestão, mediação e uso da informação. São Paulo: Editora UNESP; São Paulo: Cultura Acadêmica, 2010. p. 301-318.

MUELLER, S. M. P. O ensino de Biblioteconomia no Brasil. Ci. Inf., v. 14, n. 1, p. 3-15, jan./jun. 1985.

PINTO, E. M. História do ensino de Biblioteconomia no

Brasil: da Fundação Biblioteca Nacional à criação da 
Universidade de Brasília. 2015. 67f. Monografia (Graduação em Biblioteconomia) - Universidade de Brasília, Brasília, 2015.

PROJETO político-pedagógico do Curso de Biblioteconomia. São Luis: UFMA, 2006. 71 p.

RUSSO, L. G. M. A Biblioteconomia brasileira: Rio de Janeiro: INL, 1966. 357p.

SANT'ANNA, J. A cultura como elemento agregador para as unidades de informação: pluralizando manifestações culturais. Rev. Digit. Bibliotecon. Cienc. Inf., Campinas, v. 15, n. 1, p. 82-98, jan./abr. 2017. 